\title{
The Anticariogenic Effect of Sugar-Free Gum Containing CPP-ACP Nanocomplexes on Approximal Caries Determined Using Digital Bitewing Radiography
}

\author{
M.V. Morgan ${ }^{a} \quad$ G.G. Adams ${ }^{a} \quad$ D.L. Bailey ${ }^{a} \quad$ C.E. Tsao ${ }^{a} \quad$ S.L. Fischman ${ }^{b}$ \\ E.C. Reynolds ${ }^{a}$ \\ ${ }^{a}$ Cooperative Research Centre for Oral Health Science, School of Dental Science, Bio21 Institute,

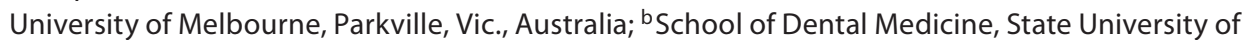 \\ New York at Buffalo, Buffalo, N.Y., USA
}

\section{Key Words \\ Approximal caries progression - Casein phosphopeptide- amorphous calcium phosphate nanocomplexes · Digital bitewing radiography $\cdot$ Enamel remineralization $\cdot$ Ordinal categorical data $\cdot$ Randomized clinical trial $\cdot$ Sugar-free chewing gum}

\begin{abstract}
This study investigated, using digital bitewing radiography, the progression and regression of approximal caries in adolescent subjects chewing a sugar-free gum containing 54 mg CPP-ACP relative to the identical gum without CPP-ACP. 2,720 subjects from 29 schools were randomly assigned to one of the two gums and were instructed to chew their assigned gum for $3 \times 10 \mathrm{~min} /$ day, with one session supervised on school days, over the 24-month study period. Standardized digital bitewing radiographs were taken at the baseline and 24-month clinical examinations for each subject. The radiographs, scored by a single examiner, were assessed for approximal surface dental caries at both the enamel and dentine level. Surface level transitions were scored using a transition matrix. Caries progression or regression was analysed using proportional-odds ordered logistic regression
\end{abstract}

\section{KARGER}

Fax +41613061234

E-Mail karger@karger.ch

www.karger.com (c) 2008 S. Karger AG, Basel

0008-6568/08/0423-0171\$24.50/0

Accessible online at:

www.karger.com/cre modelling of the transition scores at the tooth surface level. There was a statistically significant difference in the frequency distributions of the transition scores between the two gum groups ( $O R=0.82, p=0.03$ ). For subjects chewing the CPP-ACP gum the odds of a surface experiencing caries progression were $18 \%$ less than those of a surface experiencing caries progression for subjects chewing the control gum. In conclusion, the $54 \mathrm{mg}$ CPP-ACP sugar-free gum significantly slowed progression and enhanced regression of approximal caries relative to a control sugar-free gum in a 24-month clinical trial.

Copyright $\odot 2008$ S. Karger AG, Basel

The caries-preventive effectiveness of sugar-free gum has been investigated in several studies over the past 25 years. A number of controlled trials, both randomized and non-randomized, have compared sugar-free gum with a non-gum-chewing control group and there is a growing body of evidence which supports the caries-preventive nature of chewing sugar-free gum [Scheie and Fejerskov, 1998; Lingström et al., 2003; van Loveren, 2004]. The studies have generally affirmed that chewing xylitolor sorbitol-based gums is caries-preventive when com-
Eric C. Reynolds

School of Dental Science, University of Melbourne

720 Swanston Street

Parkville, Vic. 3010 (Australia)

Tel. +61 39341 1547, Fax +61 39341 1597, E-Mail e.reynolds@unimelb.edu.au 
pared to not chewing gum [Isokangas et al., 1988; Kandelman and Gagnon, 1990; Mäkinen et al., 1995, 1996; Beiswanger et al., 1998; Alanen et al., 2000; Machiulskiene et al., 2001; Szöke et al., 2001; Peng et al., 2004].

A number of trials have attempted to demonstrate the caries-preventive effectiveness of one sugar-free gum over another, usually by comparing one sugar substitute with another. The most commonly reported comparison has been between xylitol and sorbitol. In general, there have been inconsistent results when attempts have been made to demonstrate the differences between one sugarsubstituted gum over another. Whilst methodological weaknesses limit what can be inferred in terms of efficacy, the cumulative weight of evidence suggests that both xylitol-based and sorbitol-based chewing gums help reduce caries experience through salivary stimulation [Gales and Nguyen, 2000; Hayes, 2001; Maguire and Rugg-Gunn, 2003; van Loveren, 2004; Burt, 2006].

A new technology involving phosphopeptides isolated from the milk protein casein, complexed with calcium phosphate [referred to as casein-phosphopeptide amorphous calcium-phosphate (CPP-ACP) nanocomplexes], has recently been shown to be efficacious in both the prevention and reversal of enamel subsurface lesions in caries models [Reynolds et al., 1995; Shen et al., 2001; Reynolds et al., 2003; Iijima et al., 2004]. Casein phosphopeptides (CPP) containing the sequence -Ser(P)-Ser(P)Ser(P)-Glu-Glu- can stabilize calcium phosphate and prevent transformation to the insoluble phases [Cross et al., 2005]. The CPP bind to forming nanoclusters of calcium and phosphate ions in solution to form highly soluble and bioavailable nanocomplexes [Cross et al., 2005]. The anticariogenicity of the CPP-ACP nanocomplexes has been demonstrated in the rat caries model [Reynolds et al., 1995]. Further studies using human in situ caries models have shown that the CPP-ACP nanocomplexes could prevent enamel demineralization and promote enamel subsurface remineralization [Reynolds, 1998; Shen et al., 2001; Reynolds et al., 2003; Iijima et al., 2004]. In fact, recently it was shown that the CPP-ACP nanocomplexes were superior to other forms of calcium phosphate in remineralizing enamel subsurface lesions in situ [Reynolds et al., 2003]. This was attributed to the ability of the CPP to not only stabilize the calcium and phosphate as bioavailable ions, but also to localize the calcium and phosphate ions at the tooth surface thereby producing an effective concentration gradient into the subsurface enamel to promote remineralization in situ [Reynolds et al., 2003]. Iijima et al. [2004] and Cai et al. [2007] have recently shown that enamel remineralized by CPP-
ACP nanocomplexes is relatively more resistant to acid challenge when compared with normal tooth enamel. This has been attributed to the CPP-ACP nanocomplexes promoting the formation of mineral that is less soluble in acid, particularly in the presence of fluoride ions, when compared with normal carbonated tooth enamel [Iijima et al., 2004]. However, this relative resistance to acid challenge may also be attributable to the localization of the CPP-ACP at the tooth surface inhibiting enamel demineralization [Reynolds, 1998; Cai et al., 2007]. Combining the technologies of sugar-free chewing gum with supplemental use of the CPP-ACP nanocomplexes has the potential to be an important adjunct in caries prevention. In fact, a number of in situ human studies have shown that sugar-free gum is a suitable delivery vehicle for the CPPACP as the studies showed release of the CPP-ACP in a bioavailable form which provided significantly greater enamel subsurface lesion remineralization than the control sugar-free gum [Shen et al., 2001; Reynolds et al., 2003; Iijima et al., 2004; Cai et al., 2007].

An important methodological issue when evaluating new preventive or remineralizing technologies is determining the level at which dental caries diagnosis is made. The clinical endpoint of a caries lesion with loss of enamel integrity (cavitation), which is most frequently used in conventional caries studies, focuses on one end of the caries progression continuum at the expense of early caries initiation and progression [Biesbrock et al., 2004]. The reliance on cavitation as the primary endpoint and the failure to include early caries lesions in studies have resulted in poor results and outcomes for remineralization technologies [Pretty, 2006]. In low caries populations in particular, it is more appropriate to investigate the progression and regression of initial caries lesions than differences in overall caries experience.

The DMFS (decayed, missing and filled surfaces) index was developed in an era of high dental caries experience, but is a coarse measure of disease experience in populations with optimal exposure to fluoride and in which low levels of dental caries development are anticipated during the course of a clinical caries trial. Its major limitation is that the $\mathrm{D}$ component of the index relies on a binary classification of surfaces as either sound or decayed, regardless of which diagnostic threshold for caries is in use. This is at odds with the current understanding of cavitation as resulting from the failure of a normal demineralization/remineralization process that continually affects every dental surface [Imrey and Kingman, 2004]. 
In clinical studies of caries experience, the caries status of each tooth surface is determined for each subject at each examination, with examinations often repeated at several time points. Traditional methods for analysing the data obtained from these studies have involved calculating a summary measure, such as the DMF index or DMF increment, for each subject and then comparing the summary measure between study groups. The use of subject-level summary measures for comparison of efficacy or effectiveness may mask important information, such as the differences in caries susceptibility or intervention effectiveness between the various tooth surfaces [Hannigan et al., 2001; Burnside et al., 2007]. Analysing these data at the tooth surface level allows both subject-level and surfacelevel risk factors to be incorporated into the analysis. However, such analyses require that the clustering of tooth surfaces within subjects be taken into account to ensure that valid inferences are made and erroneous false-positive conclusions avoided [Hujoel et al., 1990]. Current approaches available to account for clustering include the adjustment of $\chi^{2}$ test [Donner and Banting, 1988, 1989; Ahn et al., 2002], generalized estimating equations [Liang and Zeger, 1986; DeRouen et al., 1991], clustered survival analysis [Hannigan et al., 2001], multilevel modelling [Burnside et al., 2007] and survey sampling methods [Beck et al., 1997; LaVange et al., 2001; Imrey and Kingman, 2004].

The importance of bitewing radiographs as a supplement to the clinical diagnosis of approximal caries has been confirmed in literature reviews [Kidd and Pitts, 1990; Pitts, 1996]. Bitewing radiographs generally detected more than $90 \%$ of the total number of approximal lesions found when using both clinical and radiographic examinations, whereas clinical examination generally detected less than $50 \%$ of the total approximal lesions found (depending on the clinical diagnostic threshold used) [Pitts, 1996]. The additional diagnostic value of bitewing radiographs has been confirmed in recent studies of populations with low caries experience [Hopcraft and Morgan, 2005; Llena-Puy and Forner, 2005].

A clinical study was undertaken with the objective of comparing the anticariogenicity of a CPP-ACP-containing sugar-free (sorbitol) chewing gum with that of a control sugar-free (sorbitol) chewing gum in a sample of adolescents employing usual oral hygiene practices. Sorbitol-containing sugar-free gums have been shown to prevent dental caries and, as such, a standard sorbitolbased sugar-free gum can be considered an active control. This paper reports on the progression and regression of approximal caries determined from standardized digital radiographs taken at baseline and 24 months.

\section{Subjects and Methods}

\section{Test Products}

Sugar-free chewing gum was used as the mode of delivery for the CPP-ACP nanocomplexes. Control subjects chewed the standard sorbitol-based sugar-free gum, while intervention subjects chewed an identical gum containing CPP-ACP. The sugar-free gum was provided by Cadbury Schweppes Science and Technology (N.J., USA) and was composed of approximately $50 \%$ polyols (sorbitol and mannitol), 32\% gum base, 12\% glycerin and 6\% sweeteners, colours and flavours. The concentration of CPP-ACP (Recaldent CAS 691364-49-5) in the chewing gum was 3\% w/w, equivalent to $54 \mathrm{mg}$ CPP-ACP per serving of gum, and was based on the efficacy results from human in situ CPP-ACP trials [Shen et al., 2001]. All subjects were requested to chew their gum 3 times per day for the duration of the study. The length of chewing time was $10 \mathrm{~min}$ per session. One supervised chewing session was undertaken each day at school during the school day. A teacher or student class monitor documented subject attendance at each supervised chewing session on supervised chewing session logs. The remaining sessions were unsupervised and subjects were asked to chew in their own time. To monitor these unsupervised chewing sessions, subjects were asked to complete a diary documenting their gum chewing habits. The diaries were collected and reviewed by the study team every 3 months. Subjects returning completed chewing diaries were awarded a gift voucher. For the duration of the study, each subject and household were supplied with an Australian Dental Association-approved fluoride toothpaste (Colgate Triple Cool Stripe, 1,000 ppm NaF) and soft texture toothbrush. Toothbrushes were replaced and sufficient quantities of toothpaste were distributed every 3 months together with the new supplies of chewing gum.

\section{Study Sample}

The study design was a 2-year, double-blind, parallel-group, active sorbitol-based control, randomized clinical trial. The study population consisted of male and female year 7 students, aged between 11.5 and 13.5 years, enrolled at secondary schools in the metropolitan area of Melbourne, Australia. Following agreement by a participating school, the parents/guardians of all year 7 students received an information brochure outlining the proposed clinical trial and the intention to measure the efficacy of a new preventive material for dental caries. An informed consent statement and a health and background questionnaire were also included. The statement and questionnaire were translated into five additional languages (Arabic, Cambodian, Chinese, Somali and Vietnamese). Students who returned the completed consent form and questionnaire were assessed for eligibility to undergo the baseline clinical and radiographic examinations. Subjects were included if they were in good general health and had at least eight permanent posterior teeth. Exclusion criteria included milk protein allergies, phenylketonuria, presence of fixed orthodontic appliances, chronic use of antibiotics or medications which affect salivary flow rates, and poor oral health as evidenced by rampant dental caries. Subjects were also excluded if they had previous significant exposure to radiation. Final eligibility for the study was determined following the baseline visual-tactile and radiographic examinations. Subjects who did not fulfil the entry criteria were notified, in writing, of their exclusion from the study. Twenty-nine schools were recruited progressively from April 
2001 to September 2003, until the desired sample size was reached. Schools were recruited in three cohorts: subjects in cohort 1 were recruited from April to November in 2001, subjects in cohort 2 from February to May 2002, and subjects in cohort 3 from May to September 2003. Some schools participated in multiple cohorts. Within a population with a generally low risk of caries, schools were targeted where students were likely to have a higher incidence of dental caries. This was determined from incidence data gathered from the Victorian School Dental Service and a prior study conducted by the investigators [Campain et al., 2003]. Single-sex schools were excluded to reduce gender bias. The Melbourne metropolitan water supply has been fluoridated at approximately $1.0 \mathrm{ppm}$ since 1977 .

\section{Clinical Examinations}

Subjects received a visual-tactile examination at baseline, 12 months and 24 months in classrooms at the participating schools. The clinical diagnosis of dental caries was based on a modification of the traditional criteria described in Radike [1972]. White spot lesions were diagnosed on the gingival third of the buccal or lingual/palatal surfaces only. The presence of secondary caries and sealants was also recorded.

\section{Radiographic Examinations}

Bitewing radiographs of the posterior teeth were taken at baseline and at 24 months by registered dental personnel in accordance with a standardized procedure. Subjects were able to request that copies of their radiographs be sent to their home address or their treating clinician. The radiographs were taken using a Belmont Belray 096 Dental X-ray unit (Takara Belmont Corp., Osaka, Japan, $70 \mathrm{kV}, 10 \mathrm{~mA}, 0.1 \mathrm{~s}$ exposure) and a Dexis digital X-ray system (Dexis v3.0, Provision Dental Systems, Palo Alto, Calif., USA). Total radiation exposure (baseline and 24 months) was approximately $20 \mu \mathrm{Sv}$. A purpose-built mobile dental van allowed the radiographs to be taken on site at the schools. A rigidconnection aiming device was designed, using a modification of the system described by Pitts [1983]. The Dexis sensor holders were also modified by thickening the arm, inscribing locator reference marks and the inclusion of a seven-step brass step wedge. This allowed a measure of standardization of the geometrical relationship of the sensor, the teeth and the X-ray beam between subjects and also between the baseline and 24-month examinations [Bailey et al., 2006].

\section{Scoring of Radiographic Images}

All radiographic images were scored by a single dentist (C.E.T.) over a 7-month period during 2005 in a dedicated room with controlled light level $(20 \mathrm{~lx})$ and monitor (Mitsubishi Diamond Professional 2070 SB-BK 22-inch cathode ray tube monitor) settings. Approximal surfaces, from the mesial of the first premolar to the distal of the second molar, were assessed for dental caries at both the enamel and dentine level using a modification of the scoring system described in Pitts [1984, 1985] (table 1). Overlap was recorded only when it interfered with the diagnosis of caries - a surface that displayed an overlapping image of an adjacent surface greater than one quarter of the enamel width was scored as $R_{5}$ (unreadable overlap) unless another score could be recorded with confidence (excepting $\mathrm{R}_{0}$ - sound). The radiographs were assessed without knowledge of the treatment group or any clinical diagnosis of caries; the reviewer was only informed of those teeth
Table 1. Diagnostic codes and criteria for grading of approximal lesions

\begin{tabular}{|c|c|c|}
\hline Code & Category & Diagnostic criteria \\
\hline $\mathrm{R}_{0}$ & sound & no radiolucency or restoration visible \\
\hline $\mathrm{R}_{1}$ & $\begin{array}{l}\text { outer-half } \\
\text { enamel lesion }\end{array}$ & $\begin{array}{l}\text { zone of increased radiolucency confined } \\
\text { to outer half of the enamel (no minimum } \\
\text { limit) }\end{array}$ \\
\hline $\mathrm{R}_{2}$ & $\begin{array}{l}\text { inner-half } \\
\text { enamel lesion }\end{array}$ & $\begin{array}{l}\text { zone of increased radiolucency involving } \\
\text { both inner and outer halves of the enam- } \\
\text { el, including lesions extending up to but } \\
\text { not beyond amelodentinal junction }\end{array}$ \\
\hline $\mathrm{R}_{3}$ & $\begin{array}{l}\text { outer-half } \\
\text { dentine lesion }\end{array}$ & $\begin{array}{l}\text { zone of increased radiolucency penetrat- } \\
\text { ing enamel and amelodentinal junction } \\
\text { but confined to the outer half of the } \\
\text { dentine }\end{array}$ \\
\hline $\mathrm{R}_{4}$ & $\begin{array}{l}\text { inner-half } \\
\text { dentine lesion }\end{array}$ & $\begin{array}{l}\text { zone of increased radiolucency penetrat- } \\
\text { ing into the inner half of dentine with or } \\
\text { without apparent pulpal involvement }\end{array}$ \\
\hline $\mathrm{R}_{5}$ & $\begin{array}{l}\text { unreadable } \\
\text { overlap }\end{array}$ & unreadable due to extent of overlap \\
\hline $\mathrm{R}_{6}$ & $\begin{array}{l}\text { secondary } \\
\text { caries }\end{array}$ & $\begin{array}{l}\text { zone of increased radiolucency associ- } \\
\text { ated with a filled surface }\end{array}$ \\
\hline $\mathrm{R}_{7}$ & filled surface & $\begin{array}{l}\text { radiographic appearance consistent with } \\
\text { a restoration }\end{array}$ \\
\hline $\mathrm{R}_{8}$ & not visible & tooth not visible on radiograph \\
\hline
\end{tabular}

that were deciduous or that had been scored unerupted, missing or excluded at the visual-tactile examination. Teeth were also excluded from scoring in cases of severe hypomineralization or trauma into dentine. Prior to scoring, the radiographs were contrastcorrected using a histogram equalization technique from the NIH image analysis package ImageJ (http://rsb.info.nih.gov/ij). A custom-designed database provided for a split screen interface to allow image reading and data entry. Baseline and 24-month radiographs were read in succession. For the determination of intra-examiner variability 30 complete sets of radiographs (baseline and 24-month) were assessed 3 times at random intervals during the course of the 7-month review period.

\section{Randomization and Blinding}

Within each school, all subjects (unit of randomization) who had fulfilled the entry criteria were stratified into two groups (caries-free/non-caries-free). Each school was randomized separately following the completion of the baseline clinical and radiographic examinations at the school. The study sponsor was notified of the numbers in each group and they assigned the blocks of product codes to be used for the caries-free subjects and the noncaries-free subjects (as the study sponsor was based in the USA, the blinded packaged product had been shipped to Australia by air freight in advance of randomization). Within each stratum the 
Table 2. Score transition matrix used in the analysis of the radiographic data

\begin{tabular}{lrrrrrrrrr}
\hline \multirow{2}{*}{$\begin{array}{l}\text { Baseline } \\
\text { radiographic score }\end{array}$} & \multicolumn{10}{c}{ 24-month radiographic score } \\
\cline { 2 - 10 } & $\mathrm{R}_{0}$ & $\mathrm{R}_{1}$ & $\mathrm{R}_{2}$ & $\mathrm{R}_{3}$ & $\mathrm{R}_{4}$ & $\mathrm{R}_{5}$ & $\mathrm{R}_{6}$ & $\mathrm{R}_{7}$ & $\mathrm{R}_{8}$ \\
\hline $\mathrm{R}_{0}$ & 0 & 1 & 2 & 3 & 4 & $\dagger$ & 3 & 3 & $\dagger$ \\
$\mathrm{R}_{1}$ & -1 & 0 & 1 & 2 & 3 & $\dagger$ & 2 & 2 & $\dagger$ \\
$\mathrm{R}_{2}$ & -2 & -1 & 0 & 1 & 2 & $\dagger$ & 2 & 1 & $\dagger$ \\
$\mathrm{R}_{3}$ & -3 & -2 & -1 & 0 & 1 & $\dagger$ & 0 & 0 & $\dagger$ \\
$\mathrm{R}_{4}$ & $*$ & $*$ & -2 & -1 & 0 & $\dagger$ & 0 & 0 & $\dagger$ \\
$\mathrm{R}_{5}$ & $\dagger$ & $\dagger$ & $\dagger$ & $\dagger$ & $\dagger$ & $\dagger$ & $\dagger$ & $\dagger$ & $\dagger$ \\
$\mathrm{R}_{6}$ & $*$ & $*$ & $*$ & $*$ & $*$ & $\dagger$ & 0 & 0 & $\dagger$ \\
$\mathrm{R}_{7}$ & $*$ & $*$ & $*$ & $*$ & $*$ & $\dagger$ & 0 & 0 & $\dagger$ \\
$\mathrm{R}_{8}$ & $\dagger$ & $\dagger$ & $\dagger$ & $\dagger$ & $\dagger$ & $\dagger$ & $\dagger$ & $\dagger$ & $\dagger$ \\
\hline
\end{tabular}

* = Transition impossible or extremely implausible; $\dagger=$ transition impossible to interpret.

product codes were then randomly assigned to the subjects by the study statistician (G.G.A.). The control and intervention chewing gums were identical in appearance, taste and smell. The subjects, the clinical examiners and those involved in distributing the test products were not aware of which chewing gum the subject was assigned. The investigators were provided with sealed code break envelopes, which could be used in a medical emergency. These were audited and returned unopened to the study sponsor at the completion of the study. The gum allocation was only divulged by the study sponsor upon completion of all data queries and the locking of the databases.

\section{Ethics}

Participation in the study was voluntary and both subjects and their parents/guardians gave written, informed consent. Prior to the commencement of subject recruitment, approval for the study was obtained from the University of Melbourne Human Research Ethics Committee and the Victorian Department of Education. The study was conducted in accordance with the good clinical practice guidelines of the Australian Therapeutic Goods Administration [2000]. Adherence to the protocol requirements and verification of data generation accuracy was achieved through monitoring and audit visits to the study site at periodic intervals during the study and at the completion of the study.

\section{Caries Progression}

The efficacy variable of interest was the 24-month caries progression scores on approximal surfaces. Caries progression on approximal surfaces was estimated from the radiographs using the scoring system described by Pitts [1985]. Following the reading and coding of the baseline and 24-month radiographs, the surface level transitions were scored according to the rules set out in the transition matrix (table 2). Lesion regression was accommodated in that the appropriate negative scores were given when transitions to less severe grades of lesion occurred. Only approximal tooth surfaces from the distal of the first premolar to the mesial of the second molar were included in the caries progression anal- ysis since the mesial of the first premolar and the distal of the second premolar were visible on less than $27 \%$ and $1 \%$ of radiographs, respectively. A surface scored $\mathrm{R}_{5}$ or $\mathrm{R}_{8}$ at either examination excluded that surface from the transition score calculations. Surfaces were also not scored if the corresponding tooth had been assessed as missing (due to caries), missing (non-carious), crowned or excluded at the visual-tactile examination.

\section{Compliance}

Overall compliance was calculated as the ratio of the number of supervised chewing sessions attended by the subject to the number of supervised chewing sessions that a fully compliant subject would have attended over the 24 -month period. The calculation of the number of sessions took into account weekends, school and public holidays where no supervised sessions were held. Because of difficulties associated with the non-return, completeness and veracity of the subjects' unsupervised chewing diaries, it was considered that the data obtained from the diaries were not sufficiently robust to be analysed and reported.

\section{Sample Size}

For the sample size calculation it was assumed that in the control gum group $5 \%$ of surfaces would suffer caries progression, $94.5 \%$ would remain stable and $0.5 \%$ would regress. It was also assumed that the odds ratio for caries progression for the CPPACP gum group would be 0.8 . Based on these assumptions the expected proportions of surfaces in the three categories for the CPP-ACP gum group were calculated as 4.04, 95.34 and $0.62 \%$, respectively [Whitehead, 1993]. For a one-sided 5\% significance level and $80 \%$ power the estimated number of surfaces required per group was approximately 5,150 , assuming surfaces are independent [Whitehead, 1993]. To account for clustering of surfaces within subjects it was assumed that an average of 16 of the 24 surfaces present on the radiographic images could be scored for caries progression and that the intra-class correlation was 0.10 . With these assumptions the required number of surfaces was inflated by a factor of $2.5[1+(16-1) 0.10]$ to account for the clustering. Thus the required number of surfaces required was estimated to be approximately 12,875 surfaces per gum group, equivalent to approximately 805 subjects.

\section{Statistical Analysis}

Unweighted kappa statistics [Cohen, 1960] were calculated to assess intra-examiner agreement on the scoring of the radiographic images. Cross-tabulations of the caries prevalence at the baseline and 24-month examinations and of the caries progression between the two examinations were calculated for each gum group. Odds ratios, 95\% confidence intervals and $\mathrm{p}$ values are provided for all regression models fitted. A p value of less than 0.05 was regarded as being statistically significant. All statistical analyses were performed using STATA version 10.0 software (StataCorp LP, College Station, Tex., USA).

\section{Surface Level Analyses}

A proportional odds ordered logistic regression model [McCullagh, 1980] was used to compare the caries progression between the two gum groups (model 1). Under the proportional odds model, the odds ratio is an effective one-parameter representation of a distributional shift between the score distributions of the treatment groups [Imrey and Kingman, 2004]. To assess the 
sensitivity of the scoring method, the transition scores were also collapsed into a three-category score [regression ( -3 to -1$)$, stable (0) and progression (1 to 4)] (model 2) and a dichotomous score [progression (1 to 4 ) versus no progression ( -3 to 0 )] (model 3 ). Models 1 and 2 were fitted using the svy ologit command and the proportional odds assumption tested using the brant command. Model 3 was fitted using the svy logit command. All surface level analyses were adjusted for the subject's age and sex, the quadrant (upper-right, upper-left, lower-left, lower-right) and the surface $(4 \mathrm{~d}, 5 \mathrm{~m}, 5 \mathrm{~d}, 6 \mathrm{~m}, 6 \mathrm{~d}, 7 \mathrm{~m})$. Correlations between surfaces within the same subject's mouth were adjusted for using a survey-sampling statistical approach (with schools as strata, subjects as the primary sampling unit and tooth surfaces clustered within subjects) to correct the standard errors for point estimates [Beck et al., 1997]. The results from the regression models fitted with the uncorrected variance estimates are provided for comparison purposes. Ordinal categories with counts less than 5 were combined with an adjacent category.

\section{Subject Level Analysis}

For each subject the proportion of surfaces with new or progressed lesions was calculated. The proportions were compared between gum groups using the logistic command, adjusted for the subject's age and sex (model 4).

\section{Safety}

Safety was assessed through routine adverse event monitoring. An adverse event is any untoward medical occurrence in a clinical investigation subject administered an investigational product and which does not necessarily have a causal relationship with the product [Therapeutic Goods Administration, 2000]. All subjects were followed up for any adverse events that occurred from their first examination up to 28 days after the completion of their involvement in the study. Adverse events were elicited from multiple sources including telephone calls; letters; e-mails; participating schools; gum resupplies; baseline, 12- and 24-month examinations; health update questionnaires and chewing diaries. All serious adverse events and adverse event withdrawals were reported to the Study Sponsor and the University of Melbourne Human Research Ethics Committee. All adverse events were coded from the verbatim term according to the Medical Dictionary for Regulatory Activities (MedDRA) for System Organ Class and Preferred Term.

\section{Results}

Of the 2,768 subjects screened for participation in the trial, 2,720 were randomized and 2,711 supplied with the study gums: $1,346(49.7 \%)$ received the control gum and 1,365 (50.3\%) received the gum containing CPP-ACP. Full subject disposition is presented in figure 1. At the completion of the trial, 857 subjects chewing the control gum and 892 in the group chewing the CPP-ACP gum were evaluable per protocol and with both baseline and 24-month radiographs available. The most common reasons for subject non-completion were that the subject had
Table 3. Baseline demographic and dental characteristics

\begin{tabular}{|c|c|c|}
\hline Demographic characteristic & $\begin{array}{l}\text { Control gum } \\
(\mathrm{n}=857)\end{array}$ & $\begin{array}{l}\text { CPP-ACP gum } \\
(\mathrm{n}=892)\end{array}$ \\
\hline \multicolumn{3}{|l|}{ Age } \\
\hline Mean \pm SD & $12.7 \pm 0.35$ & $12.7 \pm 0.36$ \\
\hline Range & $11.8-13.5$ & $11.5-13.5$ \\
\hline \multicolumn{3}{|l|}{ Sex } \\
\hline Male & $449(52.4 \%)$ & $479(53.7 \%)$ \\
\hline Female & $408(47.6 \%)$ & $413(46.3 \%)$ \\
\hline \multicolumn{3}{|l|}{ Country of birth } \\
\hline Australia & $737(86.0 \%)$ & $782(87.7 \%)$ \\
\hline New Zealand/Pacific Islands & $17(2.0 \%)$ & $12(1.3 \%)$ \\
\hline Europe & $19(2.2 \%)$ & $18(2.0 \%)$ \\
\hline Africa and Middle East & $14(1.6 \%)$ & $16(1.8 \%)$ \\
\hline Asia & $58(6.8 \%)$ & $51(5.7 \%)$ \\
\hline Americas & $0(0.0 \%)$ & $5(0.6 \%)$ \\
\hline Unknown & $12(1.4 \%)$ & $8(0.9 \%)$ \\
\hline \multicolumn{3}{|l|}{ Chewing gum usage } \\
\hline No & $36(4.2 \%)$ & $33(3.7 \%)$ \\
\hline Occasionally & $582(68.0 \%)$ & $629(70.7 \%)$ \\
\hline Regularly & $237(27.6 \%)$ & $228(25.6 \%)$ \\
\hline Unknown & $2(0.2 \%)$ & $2(0.2 \%)$ \\
\hline \multicolumn{3}{|l|}{ Tooth brushing } \\
\hline Two or more times per day & $391(45.6 \%)$ & $421(47.2 \%)$ \\
\hline Once a day & $390(45.5 \%)$ & $386(43.3 \%)$ \\
\hline Less than once a day & $56(6.5 \%)$ & $58(6.5 \%)$ \\
\hline Rarely & $19(2.2 \%)$ & $24(2.7 \%)$ \\
\hline Unknown & $1(0.1 \%)$ & $3(0.3 \%)$ \\
\hline \multicolumn{3}{|l|}{ Normally use fluoride toothpaste } \\
\hline Yes & $771(90.0 \%)$ & $797(89.3 \%)$ \\
\hline No & $61(7.1 \%)$ & $63(7.1 \%)$ \\
\hline Unknown & $25(2.9 \%)$ & $32(3.6 \%)$ \\
\hline \multicolumn{3}{|l|}{ Family dentist } \\
\hline Yes & $344(40.1 \%)$ & $382(42.8 \%)$ \\
\hline No & $500(58.3 \%)$ & $502(56.3 \%)$ \\
\hline Unknown & $13(1.5 \%)$ & $8(0.9 \%)$ \\
\hline \multicolumn{3}{|l|}{ Visits to dentist } \\
\hline Every 6 months & $117(13.7 \%)$ & $152(17.0 \%)$ \\
\hline Once a year & $187(21.8 \%)$ & $180(20.2 \%)$ \\
\hline Once every 2 years & $19(2.2 \%)$ & $28(3.1 \%)$ \\
\hline Less than once every 2 years & $16(1.9 \%)$ & $14(1.6 \%)$ \\
\hline When treatment required & $135(15.8 \%)$ & $135(15.1 \%)$ \\
\hline Never been & $24(2.8 \%)$ & $22(2.5 \%)$ \\
\hline Unknown & $359(41.9 \%)$ & $361(40.5 \%)$ \\
\hline \multicolumn{3}{|l|}{$\mathrm{D}_{1} \mathrm{MFT}^{\mathrm{a}}$} \\
\hline Mean \pm SD & $2.22 \pm 2.76$ & $2.18 \pm 2.75$ \\
\hline Range & $0-19$ & $0-22$ \\
\hline \multicolumn{3}{|l|}{$\mathrm{D}_{1} \mathrm{MFS}^{\mathrm{a}}$} \\
\hline Mean \pm SD & $2.80 \pm 3.85$ & $2.76 \pm 3.79$ \\
\hline Range & $0-30$ & $0-27$ \\
\hline
\end{tabular}

Data shown as number and percent (except for age, $\mathrm{D}_{1} \mathrm{MFT}$, $\mathrm{D}_{1}$ MFS).

${ }^{\text {a }}$ Based on the results of visual-tactile examinations supplemented with radiographic examinations. D component included white spot lesions. 


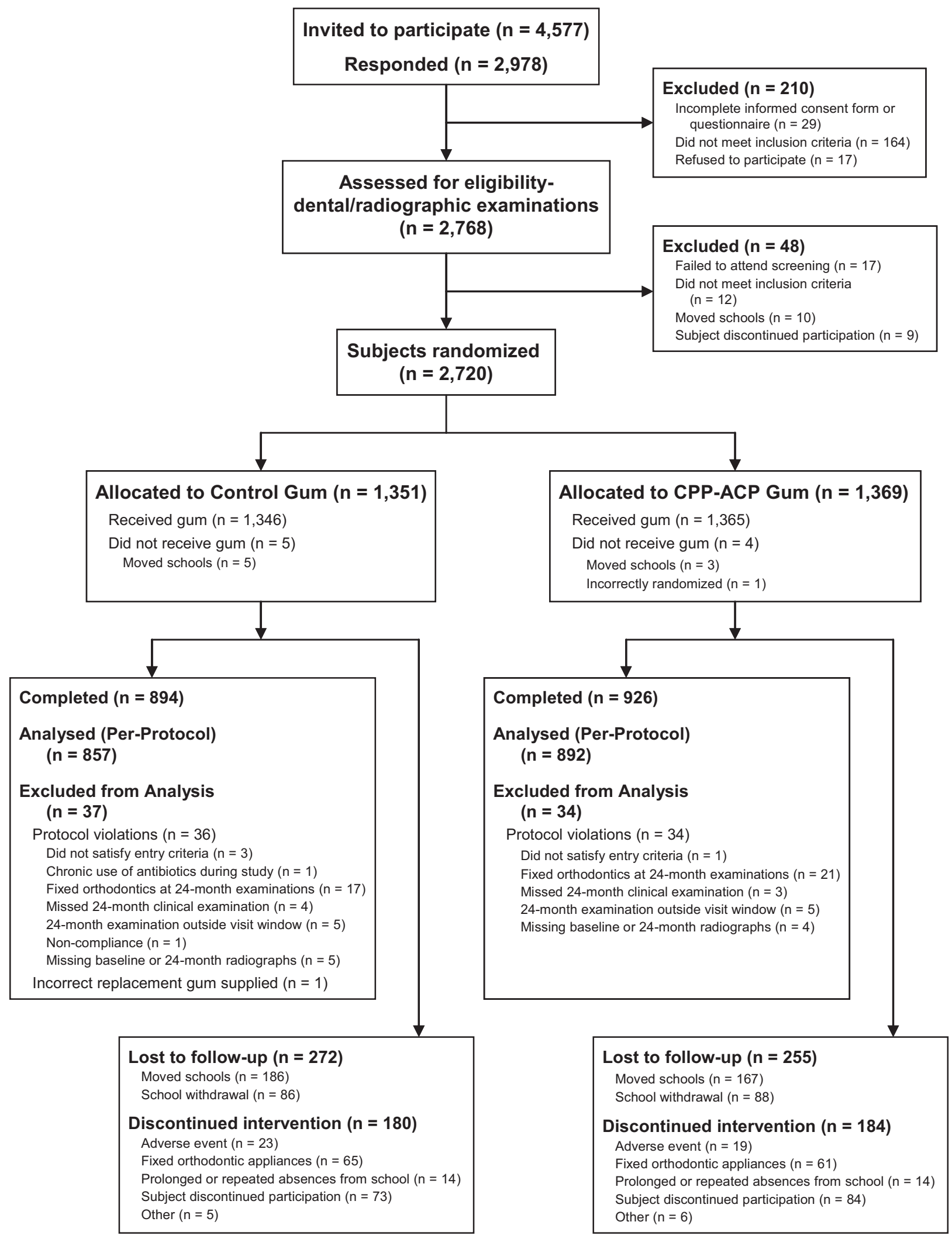

Fig. 1. Subject disposition. 
Table 4. Intra-examiner agreement on extent of penetration of lesions

\begin{tabular}{llllll}
\hline Scoring & $\begin{array}{l}\text { Surfaces } \\
\text { scored }\end{array}$ & $\begin{array}{l}\text { Complete } \\
\text { agreement }\end{array}$ & \multicolumn{2}{l}{ Discrepancy in depth code } & 3 \\
\hline Initial versus repeat 1 & 1,880 & $1,841(97.9 \%)$ & $29(1.5 \%)$ & $4(0.2 \%)$ & $6(0.3 \%)$ \\
Initial versus repeat 2 & 1,875 & $1,831(97.7 \%)$ & $33(1.8 \%)$ & $5(0.3 \%)$ & $6(0.3 \%)$ \\
Repeat 1 versus repeat 2 & 1,874 & $1,831(97.7 \%)$ & $28(1.5 \%)$ & $7(0.4 \%)$ & $8(0.4 \%)$ \\
\hline
\end{tabular}

Table 5. Baseline radiographic approximal caries diagnosis

\begin{tabular}{|c|c|c|c|c|}
\hline \multirow{2}{*}{$\begin{array}{l}\text { Baseline } \\
\text { radiographic } \\
\text { score }\end{array}$} & \multicolumn{2}{|l|}{ All surfaces } & \multicolumn{2}{|c|}{ Surfaces used in transition analysis } \\
\hline & control gum ${ }^{\mathrm{a}}$ & CPP-ACP gum ${ }^{a}$ & control gum & CPP-ACP gum \\
\hline $\mathrm{R}_{0}$ & $15,004(96.51 \%)$ & $15,717(96.79 \%)$ & $13,502(96.33 \%)$ & $14,097(96.63 \%)$ \\
\hline $\mathrm{R}_{1}$ & $237(1.52 \%)$ & $231(1.42 \%)$ & $231(1.65 \%)$ & $222(1.52 \%)$ \\
\hline $\mathrm{R}_{2}$ & $176(1.13 \%)$ & $155(0.95 \%)$ & $170(1.21 \%)$ & $151(1.04 \%)$ \\
\hline $\mathrm{R}_{3}$ & $63(0.41 \%)$ & $65(0.40 \%)$ & $61(0.44 \%)$ & $64(0.44 \%)$ \\
\hline $\mathrm{R}_{4}$ & $30(0.19 \%)$ & $26(0.16 \%)$ & $20(0.14 \%)$ & $15(0.10 \%)$ \\
\hline $\mathrm{R}_{5}$ & 2,025 & 2,016 & - & - \\
\hline $\mathrm{R}_{6}$ & $6(0.04 \%)$ & $11(0.07 \%)$ & $4(0.03 \%)$ & $9(0.06 \%)$ \\
\hline $\mathrm{R}_{7}$ & $31(0.20 \%)$ & $33(0.20 \%)$ & $29(0.21 \%)$ & $31(0.21 \%)$ \\
\hline $\mathrm{R}_{8}$ & 2,996 & 3,154 & - & - \\
\hline All & $20,568(100.00 \%)$ & $21,408(100.00 \%)$ & $14,017(100.00 \%)$ & $14,589(100.00 \%)$ \\
\hline
\end{tabular}

transferred to a non-participating school, the subject's school withdrew from the study, the subject received fixed orthodontic appliances or the subject discontinued participation for personal reasons.

\section{Baseline Characteristics}

Table 3 summarizes the demographic and caries experience characteristics of subjects. There was no difference at baseline in the average age of subjects between the two gum groups. The proportions of males and females in each gum group were similar. Although over $86 \%$ of subjects were born in Australia, the study sample was ethnically diverse. Over $95 \%$ of subjects indicated that, prior to participating in the study, they chewed gum on a regular or occasional basis. For both gum groups, over $90 \%$ of subjects brushed their teeth at least once a day, over $89 \%$ of subjects normally used fluoride toothpastes and just over $40 \%$ of subjects had a family dentist. The difference between gum groups in dental visitation was not statistically significant. There were no statistically significant differences in the baseline caries experience (DMFS/T) between the gum groups.

\section{Scoring Reliability}

The three scorings of the reliability radiographs showed excellent agreement with the intra-examiner kappa scores being 0.93 (initial vs. repeat 1), 0.92 (initial vs. repeat 2) and 0.93 (repeat 1 vs. repeat 2). The agreement between scorings on the extent of penetration of approximal lesions was evaluated from those surfaces that were scored $R_{0}, R_{1}, R_{2}, R_{3}$ and $R_{4}$ at both readings. Table 4 summarizes the agreement and discrepancies in depth codes. The radiographic scores assigned agreed for greater than $97.7 \%$ of surfaces between the three scorings. The discrepancy was greater than one depth code in less than $1 \%$ of surfaces.

\section{Baseline Caries Experience}

Table 5 summarizes the baseline radiographic approximal caries experience of subjects. There was no statisti- 
Table 6. Distribution of radiographic scores at baseline and 24 months

\begin{tabular}{|c|c|c|c|c|c|c|c|c|}
\hline \multirow{2}{*}{$\begin{array}{l}\text { Baseline } \\
\text { radiographic } \\
\text { score }\end{array}$} & \multicolumn{8}{|c|}{ 24-month radiographic score } \\
\hline & $\mathrm{R}_{0}$ & $\mathrm{R}_{1}$ & $\mathrm{R}_{2}$ & $\mathrm{R}_{3}$ & $\mathrm{R}_{4}$ & $\mathrm{R}_{6}$ & $\mathrm{R}_{7}$ & all \\
\hline \multicolumn{9}{|l|}{ Control gum } \\
\hline $\mathrm{R}_{0}$ & $12,793(94.75 \%)$ & $398(2.95 \%)$ & $255(1.89 \%)$ & $23(0.17 \%)$ & $20(0.15 \%)$ & $4(0.03 \%)$ & $9(0.07 \%)$ & $13,502(100.00 \%)$ \\
\hline $\mathrm{R}_{1}$ & $19(8.23 \%)$ & $88(38.10 \%)$ & $107(46.32 \%)$ & $11(4.76 \%)$ & $3(1.30 \%)$ & & $3(1.30 \%)$ & $231(100.00 \%)$ \\
\hline $\mathrm{R}_{2}$ & 7 (4.12\%) & $9(5.29 \%)$ & 96 (56.47\%) & $48(28.24 \%)$ & $5(2.94 \%)$ & & $5(2.94 \%)$ & $170(100.00 \%)$ \\
\hline $\mathrm{R}_{3}$ & & & $1(1.64 \%)$ & $37(60.66 \%)$ & $15(24.59 \%)$ & $1(1.64 \%)$ & $7(11.48 \%)$ & $61(100.00 \%)$ \\
\hline $\mathrm{R}_{4}$ & & & & & $14(70.00 \%)$ & & $6(30.00 \%)$ & $20(100.00 \%)$ \\
\hline $\mathrm{R}_{6}$ & & & & & & $4(100.00 \%)$ & & $4(100.00 \%)$ \\
\hline $\mathrm{R}_{7}$ & & & & & & $3(10.34 \%)$ & $26(89.66 \%)$ & $29(100.00 \%)$ \\
\hline All & $12,819(91.45 \%)$ & $495(3.53 \%)$ & $459(3.27 \%)$ & $119(0.85 \%)$ & $57(0.41 \%)$ & $12(0.09 \%)$ & $56(0.40 \%)$ & $14,017(100.00 \%)$ \\
\hline \multicolumn{9}{|c|}{ CPP-ACP gum } \\
\hline $\mathrm{R}_{0}$ & $13,484(95.65 \%)$ & $330(2.34 \%)$ & $224(1.59 \%)$ & $36(0.26 \%)$ & $9(0.06 \%)$ & $3(0.02 \%)$ & $11(0.08 \%)$ & $14,097(100.00 \%)$ \\
\hline $\mathrm{R}_{1}$ & $30(13.51 \%)$ & $84(37.84 \%)$ & $86(38.74 \%)$ & $18(8.11 \%)$ & $1(0.45 \%)$ & & $3(1.35 \%)$ & $222(100.00 \%)$ \\
\hline $\mathrm{R}_{2}$ & $9(5.96 \%)$ & $13(8.61 \%)$ & $74(49.01 \%)$ & $45(29.80 \%)$ & $4(2.65 \%)$ & $1(0.66 \%)$ & $5(3.31 \%)$ & $151(100.00 \%)$ \\
\hline $\mathrm{R}_{3}$ & $1(1.56 \%)$ & & $2(3.13 \%)$ & $31(48.44 \%)$ & $9(14.06 \%)$ & $5(7.81 \%)$ & $16(25.00 \%)$ & $64(100.00 \%)$ \\
\hline $\mathrm{R}_{4}$ & & & & & $8(53.33 \%)$ & $1(6.67 \%)$ & $6(40.00 \%)$ & $15(100.00 \%)$ \\
\hline $\mathrm{R}_{6}$ & & & & & & $8(88.89 \%)$ & $1(11.11 \%)$ & $9(100.00 \%)$ \\
\hline $\mathrm{R}_{7}$ & & & & & & $3(9.68 \%)$ & $28(90.32 \%)$ & $31(100.00 \%)$ \\
\hline All & $13,524(92.70 \%)$ & $427(2.93 \%)$ & $386(2.65 \%)$ & $130(0.89 \%)$ & $31(0.21 \%)$ & $21(0.14 \%)$ & $70(0.48 \%)$ & $14,589(100.00 \%)$ \\
\hline
\end{tabular}

The rows represent the baseline radiological appearance of approximal surfaces and the columns their appearance at the 24-month follow-up examination.

cally significant difference in the baseline caries experience between the two gum groups. The average number of tooth surfaces present in the radiographic images was $20.6 \pm 4.7$ in the control gum group and $20.6 \pm 4.5$ in the CPP gum group. At baseline, 608 subjects $(70.9 \%)$ in the control gum group and 630 subjects $(70.6 \%)$ in the CPP-ACP gum group had no approximal lesions visible on the radiographs.

\section{Compliance}

There was large variability in attendance at supervised chewing sessions, both between schools and between subjects within school. Overall, subjects in the control gum group attended an average of $64.3 \pm 17.4 \%$ of supervised chewing sessions and subjects in the CPP-ACP gum group attended an average of $63.5 \pm 17.7 \%$ of supervised chewing sessions.

\section{Approximal Caries Progression and Regression}

Table 6 displays the frequency distributions of the radiographic scores from the baseline and 24-month radiographs for subjects in the control and CPP-ACP gum groups. At baseline, 2,025 (9.8\%) and 2,015 (9.4\%) surfaces were recorded as having an unreadable overlap $\left(R_{5}\right)$
Table 7. Distribution of transition scores

\begin{tabular}{lccl}
\hline $\begin{array}{l}\text { Transition } \\
\text { score }\end{array}$ & Control gum & CPP-ACP gum & $\begin{array}{l}\text { Difference } \\
\text { in percentages }\end{array}$ \\
\hline-3 & $0(0.00 \%)$ & $1(0.01 \%)$ & +0.01 \\
-2 & $7(0.05 \%)$ & $9(0.06 \%)$ & +0.01 \\
-1 & $29(0.21 \%)$ & $45(0.31 \%)$ & +0.10 \\
0 & $13,075(93.28 \%)$ & $13,749(94.24 \%)$ & +0.96 \\
1 & $573(4.09 \%)$ & $476(3.26 \%)$ & -0.83 \\
2 & $274(1.95 \%)$ & $249(1.71 \%)$ & -0.25 \\
3 & $39(0.28 \%)$ & $51(0.35 \%)$ & +0.07 \\
4 & $20(0.14 \%)$ & $9(0.06 \%)$ & -0.08 \\
All & $14,017(100.00 \%)$ & $14,589(100.00 \%)$ & \\
\hline
\end{tabular}

for subjects in the control and CPP-ACP gum groups, respectively, whilst for the 24-month radiographs the total number of unreadable overlaps was $2,609(12.7 \%)$ and 2,758 (12.9\%), respectively. A total of $952(4.6 \%)$ and 951 (4.4\%) surfaces were coded as $\mathrm{R}_{5}$ in both the baseline and 24 -month radiographs. The majority of approximal surface carious lesions were detected radiographically, with only 72 of $522(13.8 \%)$ and 113 of 1,381 (9.1\%) untreated 
Table 8. Ordered logistic and logistic regression models for approximal caries progression

\begin{tabular}{|c|c|c|c|c|c|}
\hline & $\begin{array}{l}\text { Parameter } \\
\text { estimate }^{\mathrm{a}}\end{array}$ & $\begin{array}{l}\text { Standard } \\
\text { error }\end{array}$ & $\begin{array}{l}\text { Odds ratio } \\
(\mathrm{OR})^{\mathrm{b}}\end{array}$ & $95 \% \mathrm{CI}$ & $\mathrm{p}$ value \\
\hline \multicolumn{6}{|c|}{ Surface level analyses } \\
\hline \multicolumn{6}{|c|}{ Ordered logistic model (model 1) } \\
\hline Correlated $^{\mathrm{c}, \mathrm{d}}$ & -0.2020 & 0.0940 & 0.82 & $0.68,0.98$ & 0.03 \\
\hline Independence $^{\mathrm{d}}$ & -0.2020 & 0.0496 & 0.82 & $0.74,0.90$ & $<0.001$ \\
\hline \multicolumn{6}{|c|}{ Ordered logistic model (model 2) (regression/stable/progression) } \\
\hline Correlated $^{\mathrm{c}, \mathrm{d}}$ & -0.2044 & 0.0940 & 0.82 & $0.68,0.98$ & 0.03 \\
\hline Independence ${ }^{\mathrm{d}}$ & -0.2044 & 0.0493 & 0.82 & $0.74,0.90$ & $<0.001$ \\
\hline \multicolumn{6}{|c|}{ Logistic model (model 3) (no progression/progression) } \\
\hline Correlated ${ }^{c, d}$ & -0.1955 & 0.1001 & 0.82 & $0.67,1.00$ & 0.05 \\
\hline Independence ${ }^{\mathrm{d}}$ & -0.1955 & 0.0506 & 0.82 & $0.74,0.91$ & $<0.001$ \\
\hline \multicolumn{6}{|c|}{ Subject level analysis } \\
\hline \multicolumn{6}{|c|}{ Logistic model (model 4) (no progression/progression) } \\
\hline Independence ${ }^{\mathrm{e}}$ & -0.2259 & 0.1019 & 0.80 & $0.65,0.97$ & 0.03 \\
\hline $\begin{array}{l}{ }^{\mathrm{a}} \text { Estimate of the } \\
\log \text { odds scale. } \\
{ }_{\mathrm{b}} \text { An OR }<1 \text { imp } \\
\text { than the odds for a } \\
{ }^{\mathrm{c}} \text { Standard error } \\
\text { primary sampling } \mathrm{u} \\
{ }_{\mathrm{d}} \text { Terms in mode } \\
6 \mathrm{~m}, 6 \mathrm{~d}, 7 \mathrm{~m}) . \\
{ }^{\mathrm{e}} \text { Model adjusted }\end{array}$ & $\begin{array}{l}\text { s progression } \\
\text { f a surface pr } \\
\text { for subjects } i \\
\text { relations bet } \\
\text { (upper right, }\end{array}$ & $\begin{array}{l}\text { tween gum } \\
\text { ressing for s } \\
\text { he control g } \\
\text { n surfaces } \\
\text { per left, low }\end{array}$ & $\begin{array}{l}\text { ups (CPP-AC } \\
\text { group. } \\
\text { ng survey sa } \\
\text { eft, lower righ }\end{array}$ & $\begin{array}{l}\text { gum - cont } \\
\text { pling metho } \\
\text { and surface }\end{array}$ & $\begin{array}{l}\text { lgum) on } \\
\text { (sup is less } \\
\text { d, } 5 \mathrm{~m}, 5 \mathrm{~d} \text {, }\end{array}$ \\
\hline
\end{tabular}

Table 9. Summary of treatment-emergent adverse events

\begin{tabular}{lcc}
\hline & $\begin{array}{l}\text { Control gum } \\
(\mathrm{n}=1,346)\end{array}$ & $\begin{array}{l}\text { CPP-ACP gum } \\
\text { (n = 1,365) }\end{array}$ \\
\hline Subjects with any adverse event & $829(61.6 \%)$ & $844(61.8 \%)$ \\
Subjects with serious adverse events & $33(2.5 \%)$ & $30(2.2 \%)$ \\
Subjects with non-serious adverse events related to study gums & $93(6.9 \%)$ & $90(6.6 \%)$ \\
Subjects with serious adverse events related to study gums ${ }^{\mathrm{a}}$ & $0(0.0 \%)$ & $0(0.0 \%)$ \\
Subjects who discontinued the study due to adverse events & $23(1.7 \%)$ & $19(1.4 \%)$ \\
Total number of adverse events recorded & 1,769 & 1,830 \\
\hline
\end{tabular}

${ }^{a}$ Considered by the investigators as possibly or probably related to the study gums.

lesions being detected clinically at the baseline and 24month examinations, respectively (for consistency with the visual-tactile examinations, radiographic scores $R_{0}$ and $\mathrm{R}_{1}$ were considered sound).

The frequency distribution of the transition scores is summarized by gum group in table 7 . The number of tooth surfaces per subject for which transitions were scored ranged from 3 to 24 (average $16.4 \pm 5.1$ ) in the control gum group and from 4 to 24 (average $16.4 \pm 4.9$ ) in the CPP-ACP gum group. The baseline caries experience in transition surfaces was similar to the baseline caries experience summarized in table 5. The CPP-ACP gum slowed progression of carious lesions (transition scores 1 to 4) compared to the control gum: 785 of 14,589 approximal surfaces (5.4\%) experienced caries progression with the CPP-ACP gum compared to 906 of 14,017 approximal 
Table 10. Most common adverse events reported

\begin{tabular}{lcc}
\hline MedDRa preferred term & $\begin{array}{c}\text { Control gum } \\
(\mathrm{n}=1,346)\end{array}$ & $\begin{array}{l}\text { CPP-ACP gum } \\
(\mathrm{n}=1,365)\end{array}$ \\
\hline $\begin{array}{l}\text { Most common adverse events } \\
\text { (i.e. those occurring in more than 5\%) }\end{array}$ \\
Malaise & $565(42.0 \%)$ & $567(41.5 \%)$ \\
Headache & $122(9.1 \%)$ & $99(7.3 \%)$ \\
Nasopharyngitis & $106(7.9 \%)$ & $99(7.3 \%)$ \\
Influenza & $82(6.1 \%)$ & $104(7.6 \%)$ \\
Most common treatment-related adverse events & \\
(i.e. those occurring in more than $1 \%)$ & \\
Nausea & $15(1.1 \%)$ & $23(1.7 \%)$ \\
Headache & $25(1.9 \%)$ & $11(0.8 \%)$ \\
Diarrhoea & $6(0.4 \%)$ & $13(1.0 \%)$ \\
Most common adverse event discontinuation reasons \\
Nausea & $3(0.2 \%)$ & $9(0.7 \%)$ \\
Headache & $6(0.4 \%)$ & $3(0.2 \%)$ \\
Diarrhoea & $1(0.1 \%)$ & $3(0.2 \%)$ \\
\hline
\end{tabular}

surfaces (6.5\%) with the control gum, a reduction of $17 \%$. The CPP-ACP gum also enhanced regression of carious lesions (transition scores -3 to -1 ) compared to the control gum: 55 approximal surfaces $(0.4 \%)$ experienced caries regression with the $\mathrm{CPP}-\mathrm{ACP}$ gum compared to 36 approximal surfaces $(0.3 \%)$ with the control gum. A greater percentage of approximal surfaces also remained unchanged with the CPP-ACP gum (94.2\%) than with the control gum (93.3\%).

\section{Surface Level Analyses}

The differences in the transition score distributions between the two gum groups were statistically significant (table 8, model 1: $\mathrm{p}=0.03$ ). The odds ratio was estimated as 0.82 . Overall, the odds of a surface experiencing caries progression for subjects in the CPP-ACP gum group was $18 \%$ less than the odds of a surface experiencing caries progression for subjects in the control gum group. The odds of caries progression also increased with age $(\mathrm{p}=$ $0.03)$ and differed between surfaces ( $\mathrm{p}<0.001)$, with surfaces $5 \mathrm{~d}, 6 \mathrm{~m}, 6 \mathrm{~d}$ and $7 \mathrm{~m}$ having significantly more caries progressions than surfaces $4 \mathrm{~d}$ and $5 \mathrm{~m}$. No significant differences in caries progression were found between males and females $(\mathrm{p}=0.5)$ or between quadrants of the mouth $(\mathrm{p}=0.2)$, and no gum interaction terms were significant. No departure from the proportional odds assumption was found $(p=0.2)$. The results from model 2 in table 8 were almost identical to the results above for the full model (model 1). The odds ratio and 95\% confidence interval for model 3 were also similar to those obtained from mod- els 1 and 2. The major difference was that the odds ratio for caries progression on surface $6 \mathrm{~m}$ was now $2.42 \mathrm{com}$ pared to 1.86 with the other models. This was not surprising since 71 of 91 surfaces with negative transitions were from surface $6 \mathrm{~m}$ and these were now coded as not progressing. The standard errors estimated from the models that assumed independence were approximately half the standard errors estimated for the survey sampling models that adjusted for the correlation between tooth surfaces (the estimated intra-class correlation was 0.12).

\section{Subject Level Analyses}

The average number of surfaces that experienced caries progression was 1.42 surfaces per 24 surfaces in the control gum group and 1.23 surfaces per 24 surfaces in the CPP-ACP gum group. For 615 subjects (68.9\%) in the CPP-ACP gum group compared with 548 subjects (63.9\%) in the control gum group, all scorable approximal surfaces either remained unchanged or experienced caries regression. The estimated $\mathrm{OR}$ for caries progression from the logistic regression was $0.80(\mathrm{p}=0.03$, table 8 , model 4). The odds of a surface experiencing caries progression for subjects in the CPP-ACP gum group was 20\% less than the odds of a surface experiencing caries progression for subjects in the control gum group.

\section{Safety}

Table 9 summarizes the adverse events which occurred after the first examination (treatment-emergent adverse events) for the randomized population. Table 10 shows the most common adverse events reported in either group, the non-serious adverse events most frequently assessed as related to use of the study gums (nausea, headache and diarrhoea) and the most common reasons for adverse event discontinuation. All serious adverse events were assessed by the investigators as not being related to the gum usage. For 3 subjects the serious adverse event (although not product-related) resulted in their discontinuation from the study. The incidences of adverse events (serious and non-serious) were similar between the two study gums.

\section{Discussion}

The trial compared the effectiveness of a CPP-ACP gum over an active control. There is little scientific literature which is directly comparable to this study where a control sugar-free gum was compared to a similar gum with an additional caries-preventive agent. All reason- 
able attempts were made to test the CPP-ACP gum in a situation where it could reasonably be expected that dental caries might be unlikely to occur and in an environment where dental caries development is low. Subjects from both groups were exposed to fluoridated drinking water and they, and their families, were provided with a constant supply of fluoridated toothpaste and toothbrushes. All subjects were notified on an annual basis of their oral health status and copies of their radiographs supplied to their chosen dental care provider. In addition to the above preventive dental caries programme, subjects in both groups were supervised in the use of sugarfree chewing gum. To the extent that it was possible to control in a large clinical trial, the only point of difference in terms of dental caries prevention was the inclusion of CPP-ACP in the sugar-free gum used by one group of subjects.

Despite these intended stringencies in the trial design, chewing CPP-ACP afforded an increased preventive effect beyond that achieved through good, basic oral care habits and the use of chewing sugar-free gum. Subjects chewing the CPP-ACP sugar-free gum demonstrated a statistically significant difference in radiographically diagnosed approximal carious lesions compared with those chewing the control sugar-free gum. The level to which this result is clinically significant is worth considering. Given that the population in which the study was conducted can be considered 'low risk', the difference in approximal caries development is indicative of the clinical strength of the effect. In addition, the ethnically diverse study population promotes the generalizability of the study results.

The results of this trial have been presented using data obtained from standardized digital radiographs. The assessment of the effectiveness of a preventive agent where incipient lesion detection is key (in an era of low dental caries and in populations of low risk) requires diagnostic criteria which are highly refined and reproducible. Whilst historically, reliance has been placed on measurements obtained from clinical examinations, for the purposes of early lesion detection such measurements can no longer be considered appropriate, especially in the current oral disease environment. A recent review of approximal caries diagnosis reported higher sensitivities for bitewing radiography than fibre-optic transillumination and visualtactile assessment [Bader et al., 2001]. An additional advantage of radiographs is that the images can be stored indefinitely and are able to be reviewed under standardized conditions at any time. Results of this study were restricted to approximal surfaces. From a clinical stand- point the diagnosis of occlusal lesions using radiographs, particularly those confined to enamel, is poor [Wenzel and Fejerskov, 1992; Kidd et al., 2003; Hopcraft and Morgan, 2005]. The use of radiography is not new in dentistry, although its use has been limited in clinical trials because of ethical issues regarding cumulative radiation dosage, together with practicalities of access and cost. The radiographic methodology used in this study (standardized measurements, low dosage exposure and digital recording, and the use of a dedicated on-site radiography van) ensured that the effect of these issues was minimized. Standardized digital radiography procedures in conjunction with a scoring method that grades lesion depth provide potentially the most appropriate method of determining early carious lesion development in largescale caries clinical trials and are particularly appropriate in a low caries population. This study also confirmed the value of bitewing radiographs for detecting approximal carious lesions in clinical trials. The additional diagnostic yield from the bitewing radiographs was substantial: greater than 6-fold and greater than 11-fold for the baseline and 24-month examinations, respectively.

Previous investigations [Lawrence et al., 1997; Lawrence and Sheiham, 1997; Chesters et al., 2002] using a similar radiography scoring system also reported good reliability (kappa scores of $\sim 0.8$ ). The use of transition scores to interpret the progression (and regression) of approximal caries in longitudinal studies [Grondahl et al., 1977; Granath et al., 1980; Cook, 1984; Källestål and Holm, 1994; Lawrence and Sheiham, 1997] and in clinical trials [Chesters et al., 2002] has become an accepted analytical methodology.

The results from the surface level analyses mirrored the results from the subject level analysis. An advantage of the surface level analyses was that they confirmed the differing susceptibility of approximal surfaces to caries progression found in other studies [Dummer et al., 1988; Mejàre et al., 1999; Hintze, 2001; Stenlund et al., 2003]. This paper also illustrated the need for statistical analysis to account for the clustering of surfaces within subjects that has been reported in other studies. The assumption of independence of tooth surfaces within a subject resulted in a twofold underestimation of the standard errors for the treatment difference and resulted in exaggerated $\mathrm{p}$ values for the comparison between the gum groups. Dichotomizing the transition scores leads to a loss of efficiency for the comparison between gum groups since caries regressions are discounted.

Several studies using an in situ remineralization model have demonstrated that the CPP-ACP nanocomplexes 
delivered in a sugar-free gum, as used in this clinical trial, significantly remineralized enamel subsurface lesions [Shen et al., 2001; Reynolds et al., 2003; Iijima et al., 2004; Cai et al., 2007]. In the current clinical trial we observed not only a smaller number of approximal surfaces that progressed but also a greater number of surfaces (lesions) that regressed (remineralized) with the CPP-ACP gum compared with the control sugar-free gum. The regressions involved predominantly remineralization of enamel lesions (e.g. inner-half enamel lesion to sound; outerhalf enamel lesion to sound and inner-half enamel lesion to outer-half enamel lesion) but also a smaller number of dentine lesions that remineralized (e.g. outer-half dentine lesion to inner-half enamel lesion). These clinical trial results therefore confirm the findings from the shortterm in situ remineralization studies and demonstrate that the longer-term manifestation of enamel subsurface lesion remineralization and inhibition of demineralization by the CPP-ACP nanocomplexes is the significant slowing of caries progression. In conclusion, chewing sugar-free gum containing CPP-ACP can be regarded as an additional caries prevention tool, over and above other accepted preventive strategies such as water fluoridation or fluoridated toothpaste.

\section{Acknowledgements}

The authors would like to acknowledge the significant contributions to the design, execution and analysis of this study made by staff members from the Clinical Trial Group at the School of Dental Science, The University of Melbourne; Dr. D. Tancredi, Dr. D. Ming and staff members of Cadbury Schweppes Science and Technology, and the trial monitor, Mr. M. Boschenok. This study would not have been possible without the cooperation of the Victorian Department of Education and the principals, teachers, parents and students at the participating schools. Support for this study was provided by Cadbury Schweppes Science and Technology and the Australian National Health and Medical Research Council Development Grant No. 991501.

\section{References}

Ahn C, Jung SH, Donner A: Application of an adjusted $\chi^{2}$ statistic to site-specific data in observational dental services. J Clin Periodontol 2002;29:79-82.

-Alanen P, Isokangas P, Gutmann K: Xylitol candies in caries prevention: results of a field study in Estonian children. Community Dent Oral Epidemiol 2000;28:218-224.

-Bader JD, Shugars DA, Bonito AJ: Systematic reviews of selected dental caries diagnostic and management methods. J Dent Educ 2001;65: 960-968.

Bailey DL, Adams GG, Tsao CE, Morgan MV: Standardisation of digital bitewing radiographs during a clinical caries trial (abstract 62). Caries Res 2006;40:324.

Beck JD, Lawrence HP, Koch GG: Analytic approaches to longitudinal caries data in adults. Community Dent Oral Epidemiol 1997;25:42-51.

-Beiswanger BB, Boneta AE, Mau MS, Katz BP, Proskin HM, Stookey GK: The effect of chewing sugar-free gum after meals on clinical caries incidence. J Am Dental Assoc 1998;129:1623-1626.

Biesbrock AR, Chesters RK, Ellwood RP, Smith SR: The challenges of validating diagnostic methods relative to a conventional two-year caries clinical trial. J Dent Res 2004;83:C53C55.

Burnside G, Pine CM, Williamson PR: The application of multilevel modelling to dental caries data. Stat Med 2007;26:4139-4149.
Burt BA: The use of sorbitol- and xylitol-sweetened chewing gum in caries control. J Am Dental Assoc 2006;137:190-196.

Cai F, Manton DJ, Shen P, Walker GD, Cross KJ, Yuan Y, Reynolds C, Reynolds EC: Effect of addition of citric acid and casein phosphopeptide-amorphous calcium phosphate to a sugar-free chewing gum on enamel remineralization in situ. Caries Res 2007;41:377383.

Campain AC, Morgan MV, Evans RW, Ugoni A, Adams GG, Conn JA, Watson MJ: Sugarstarch combinations in food and the relationship to dental caries in low-risk adolescents. Eur J Oral Sci 2003;111:316-325.

Chesters RK, Pitts NB, Matuliene G, Kvedariene A, Huntington E, Bendinskaite R, Balciuniene I, Matheson JR, Nicholson JA, Gendvilyte A, Sabalaite R, Ramanauskiene J, Savage D, Mileriene J: An abbreviated caries clinical trial design validated over 24 months. J Dent Res 2002;81:637-640.

Cohen J: A coefficient of agreement for nominal scales. Educ Psychol Meas 1960;20:37-46.

Cook SR: A longitudinal radiographic study of caries progression in dental students. Aust Dent J 1984;29:315-320.

Cross KJ, Huq NL, Palamara JE, Perich JW, Reynolds EC: Physicochemical characterization of casein phosphopeptide-amorphous calcium phosphate nanocomplexes. J Biol Chem 2005;280:15362-15369.
DeRouen TA, Mancl L, Hujoel P: Measurement of associations in periodontal diseases using statistical methods for dependent data. J Periodontal Res 1991;26:218-229.

Donner A, Banting D: Analysis of site-specific data in dental statistics. J Dent Res 1988;67: 1392-1395.

Donner A, Banting D: Adjustment of frequently used chi-square procedures for the effect of site-to-site dependencies in the analysis of dental data. J Dent Res 1989;68:1350-1354.

Dummer PMH, Addy M, Oliver SJ, Shaw WC: Changes in the distribution of decayed and filled tooth surfaces and the progression of approximal caries in children between the ages of 11-12 years and 15-16 years. Br Dent J 1988;164:277-282.

Gales MA, Nguyen TM: Sorbitol compared with xylitol in prevention of dental caries. Ann Pharmacother 2000;34:98-100.

Granath L, Kahlmeter A, Matsson L, Schroder $\mathrm{U}$ : Progression of proximal enamel caries in early teens related to caries activity. Acta Odontol Scand 1980;38:247-251.

Grondahl HG, Hollender L, Malmcrona E, Sundquist B: Dental caries and restorations in teenagers. Swed Dent J 1977;1:45-50.

Hannigan A, O’Mullane DM, Barry D, Schafer F, Roberts AJ: A re-analysis of a caries clinical trial by survival analysis. J Dent Res 2001;80: 427-431.

Hayes C: The effect of non-cariogenic sweeteners on the prevention of dental caries: a review of the evidence. J Dent Educ 2001;65: 1105-1109. 
Hintze H: Approximal caries prevalence in Danish recruits and progression of caries in the late teens: a retrospective radiographic study. Caries Res 2001;35:27-35.

-Hopcraft MS, Morgan MV: Comparison of radiographic and clinical diagnosis of approximal and occlusal dental caries in a young adult population. Community Dent Oral Epidemiol 2005;33:212-218.

-Hujoel PP, Loesche WJ, DeRouen TA: Assessment of relationships between site-specific variables. J Periodontol 1990;61:368-372.

- Iijima Y, Cai F, Shen P, Walker G, Reynolds C, Reynolds EC: Acid resistance of enamel subsurface lesions remineralized by a sugarfree chewing gum containing casein phosphopeptide-amorphous calcium phosphate. Caries Res 2004;38:551-556.

-Imrey PB, Kingman A: Analysis of clinical trials involving non-cavitated caries lesions. J Dent Res 2004;83:C103-C108.

- Isokangas P, Alanen P, Tiekso J, Mäkinen KK Xylitol chewing gum in caries prevention: a field study in children. J Am Dental Assoc 1988;117:315-320.

Källestål C, Holm AK: Allocation of dental caries prevention in Swedish teenagers. Community Dent Oral Epidemiol 1994;22:100105.

Kandelman D, Gagnon G: A 24-month clinical study of the incidence and progression of dental caries in relation to consumption of chewing gum containing xylitol in school preventive programs. J Dent Res 1990;69: 1771-1775.

Kidd EAM, Mejàre I, Nyvad B: Clinical and radiographic diagnosis; in Fejerskov O, Kidd EAM (eds): Dental Caries: The Disease and Its Clinical Management. Oxford, Blackwell, 2003, pp 111-128.

Kidd EAM, Pitts NB: A reappraisal of the value of the bitewing radiograph in the diagnosis of posterior approximal caries. Br Dent J 1990;169:195-200.

-LaVange LM, Koch GG, Schwartz TA: Applying sample survey methods to clinical trials data. Stat Med 2001;20:2609-2623.

Lawrence HP, Benn DK, Sheiham A: Digital radiographic measurement of approximal caries progression in fluoridated and non-fluoridated area of Rio de Janeiro, Brazil. Community Dent Oral Epidemiol 1997;25: 412-418.

Lawrence HP, Sheiham A: Caries progression in 12- to 16-year-old schoolchildren in fluoridated and fluoride-deficient areas in Brazil. Community Dent Oral Epidemiol 1997;25: 402-411.
Liang KY, Zeger SL: Longitudinal data analysis using generalized linear models. Biometrics 1986;73:13-22.

Lingström P, Holm AK, Mejàre I, Twetman S, Söder B, Norlund A, Axelsson S, Lagerlöf F, Nordenram G, Petersson LG, Dahlgren H, Källestål C: Dietary factors in the prevention of dental caries: a systematic review. Acta Odontol Scand 2003;61:331-340.

Llena-Puy C, Forner L: A clinical and radiographic comparison of caries diagnosed in approximal surfaces of posterior teeth in a low-risk population of 14 -year-old children. Oral Health Prev Dent 2005;3:47-52.

Machiulskiene V, Nyvad B, Baelum V: Caries preventive effect of sugar-substituted chewing gum. Community Dent Oral Epidemiol 2001;29:278-288.

Maguire A, Rugg-Gunn AJ: Xylitol and caries prevention - is it a magic bullet? Br Dent J 2003;194:429-436.

Mäkinen KK, Bennett CA, Hujoel PP, Isokangas PJ, Isotupa KP, Pape Jr HR, Mäkinen PL: Xylitol chewing gums and caries rates: a 40month cohort study. J Dent Res 1995;74: 1904-1913.

Mäkinen KK, Mäkinen PL, Pape HR Jr, Peldyak J, Hujoel PP, Isotupa KP, Isokangas PJ, Allen P, Bennett C: Conclusion and review of the 'Michigan Xylitol Programme' (1986-1995) for the prevention of dental caries. Int Dent J 1996;46:22-34.

McCullagh P: Regression models for ordinal data. J R Statist Soc B 1980;42:109-142.

-Mejàre I, Källestål C, Stenlund H: Incidence and progression of approximal caries from 11 to 22 years of age in Sweden: a prospective radiographic study. Caries Res 1999;33:93100.

Peng B, Petersen PE, Bian Z, Tai B, Jiang H: Can school-based oral health education and a sugar-free chewing gum program improve oral health? Results from a two-year study in PR China. Acta Odontol Scand 2004;62:328332.

Pitts NB: The use of film holding, beam collimating and aiming devices in bitewing radiography: a suggested design for routine and research use. Dentomaxillofac Radiol 1983; 12:77-82.

Pitts NB: Systems for grading approximal carious lesions and overlaps diagnosed from bitewing radiographs: proposals for future standardization. Community Dent Oral Epidemiol 1984;12:114-122.

Pitts NB: Score system for behaviour of radiologically diagnosed approximal carious lesions. Community Dent Oral Epidemiol 1985;13:268-272.
Pitts NB: The use of bitewing radiographs in the management of dental caries: scientific and practical considerations. Dentomaxillofac Radiol 1996;25:5-16.

Pretty IA: Caries detection and diagnosis: novel techniques. J Dent 2006;34:727-739.

Radike AW: Criteria for diagnosis of dental caries; in Conference on the Clinical Testing of Cariostatic Agents. American Dental Association, 1972, pp 87-88.

Reynolds EC: Anticariogenic complexes of amorphous calcium phosphate stabilized by casein phosphopeptides: a review. Spec Care Dentist 1998;18:8-16.

Reynolds EC, Cai F, Shen P, Walker GD: Retention in plaque and remineralization of enamel lesions by various forms of calcium in a mouthrinse or sugar-free chewing gum. J Dent Res 2003;82:206-212.

Reynolds EC, Cain CJ, Webber FL, Black CL, Riley PF, Johnson IH, Perich JW: Anticariogenicity of calcium phosphate complexes of tryptic casein phosphopeptides in the rat. J Dent Res 1995;74:1272-1279.

Scheie AA, Fejerskov OB: Xylitol in caries prevention: what is the evidence for clinical efficacy? Oral Dis 1998;4:268-278.

Shen P, Cai F, Nowicki J, Vincent J, Reynolds EC: Remineralization of enamel subsurface lesions by sugar-free chewing gum containing casein phosphopeptide-amorphous calcium phosphate. J Dent Res 2001;80:2066-2070.

Stenlund H, Mejàre I, Källestål C: Caries incidence rates in Swedish adolescents and young adults with particular reference to adjacent approximal tooth surfaces: a methodological study. Community Dent Oral Epidemiol 2003;31:361-367.

-Szöke J, Bánóczy J, Proskin HM: Effect of aftermeal sucrose-free gum-chewing on clinical caries. J Dent Res 2001;80:1725-1729.

Therapeutic Goods Administration: Note for guidance on good clinical practice (cpmp/ ich/135/95) annotated with TGA comments. Canberra, Therapeutic Goods Administration, 2000.

van Loveren C: Sugar alcohols: what is the evidence for caries-preventive and caries-therapeutic effects? Caries Res 2004;38:286-293.

Wenzel A, Fejerskov O: Validity and diagnosis of questionable caries lesions in occlusal surfaces of extracted third molars. Caries Res 1992;26:188-194.

Whitehead J: Sample size calculations for ordered categorical data. Stat Med 1993;12: 2257-2271. 